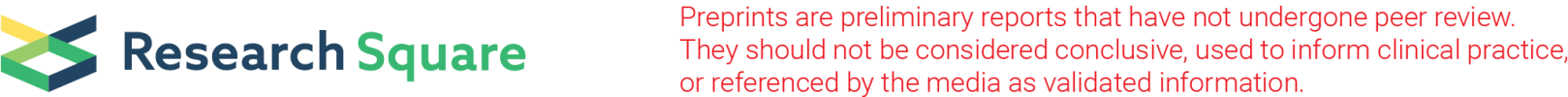

\section{Survival analysis of radical prostatectomy and brachytherapy in the treatment of early-stage localized prostate cancer}

Qun Xie ( $\nabla$ xq1179354947@163.com )

Zhuhai City People's Hospital

Huafu Li

Sun Yat-sen University Zhongshan School of Medicine

Xiao Ye

Zhuhai City People's Hospital

Ya Xu

Zhuhai City People's Hospital

Xiaoxu Yuan

Zhuhai City People's Hospital

Research article

Keywords: prostate neoplasms, brachytherapy, prostatectomy, SEER program

Posted Date: July 18th, 2019

DOI: https://doi.org/10.21203/rs.2.11543/v1

License: (c) (1) This work is licensed under a Creative Commons Attribution 4.0 International License. Read Full License 


\section{Abstract}

Objective Brachytherapy is minimally invasive with few complications, so may be a good alternative to surgery for patients with prostate cancer. This study aimed to compare the therapeutic effects of brachytherapy and radical prostatectomy in the treatment of localized prostate cancer at different stages. Methods A total of 16532 patients pathologically diagnosed with prostate cancer who underwent radical prostatectomy and 16627 patients who underwent brachytherapy between 2010 and 2012 were collected through the Surveillance, Epidemiology, and End Results (SEER) Stat software. These patients were randomly matched based on age and prostate specific antigen (PSA) level at first diagnosis, and were divided into five subgroups, including G2T1c, G3T1c, G2T2a, G3T2a and G3T3b. Differences in survival were analyzed by Kaplan-Meier survival curves and compared by log-rank test. Results The overall survival (OS) and prostate cancer-specific death time (PCSDT) in the radical prostatectomy group at G3T1c stage were significantly longer than in the brachytherapy group $(P<0.05)$, and OS, but not PCSDT, was longer than the brachytherapy group at G2T2a stage ( $P=0.02)$. But at the G2T1c, G3T2a and G3T3b stages OS and PCSDT were not significantly different between the two treatments $(P>0.05)$. Conclusion The radical prostatectomy prognosis was superior to brachytherapy in the treatment of early-stage lowrisk localized prostate cancer, whereas there was no significant difference in the prognosis of patients with moderate or high-risk localized prostate cancer.

\section{Background}

With economic development, advanced aging and steady improvement in public health, prostate cancer has become a global problem threatening middle-aged and elderly males. Over one million males are diagnosed with prostate cancer, and over 300,000 people die of prostate cancer each year.(1) Early diagnosis of early-stage localized prostate cancer may improve this by screening programs for prostate specific antigen (PSA).(2) According to the American Association for the Study of the Prostate Cancer Strategy (CaPSURE), patients with low-risk prostate cancer account for $70 \%$ of the total patients with prostate cancer.( 3 )

Radical prostatectomy is still the gold standard for the treatment of low-risk prostate cancer. It is one of the most effective ways to treat localized prostate cancer, and $30-50 \%$ of newly diagnosed patients are physically eligible to undergo the risk of surgery. (4) In addition, laparoscopic and robot-assisted laparoscopic radical prostatectomy has improved prognosis after prostatectomy.(5) These modern developments also effectively control treatment side-effects.( 6)

However, brachytherapy brings hope to elderly patients with prostate cancer who have poorer physical condition and significant surgical contraindications. Brachytherapy is a good choice for patients who are unsuitable or unwilling to undergo surgery, and this method has been accepted in North America and some European countries. (7) According to the guidelines of the American Society of Brachytherapy (ABS), brachytherapy is suitable for all types of prostate cancers.( 8) Brachytherapy has the advantages of minimal invasion, easily accepted by the patients and few complications. A 12-year follow-up study 
has demonstrated that the prognosis of brachytherapy is not significantly different with the radical prostatectomy. (9) Moreover, meta-analysis of 4 studies has shown that there is no significant difference in the 5-year survival rate between radical prostatectomy and brachytherapy in the treatment of localized prostate cancer.(10) Nevertheless, the above studies enrolled small numbers of patients, and lacked detailed analysis of the influence of the various pathological stages of the cancer on the treatment.

The surveillance, epidemiology and end result (SEER) database of the National Cancer Institute has registered detailed information for millions of cancer patients in America since 1973; such as their treatment, pathology and prognosis. Therefore, this study consulted the SEER database for data of patients with localized prostate cancer to compare the outcomes of the two methods. This allowed detailed analysis of patients with prostate cancer at different stages, to evaluate the indications for radical prostatectomy and brachytherapy.

\section{Methods}

\section{patients}

Patients who were pathologically diagnosed with prostate cancer from January 2010 to December 2012 were collected from the SEER database using the SEER Stat software (surveillance, epidemiology, and end results program institute SEER State software, version 8.3.2). All SEER data base information were deidentified by United States institutional review board approval.The inclusion criteria were: (1) Patients aged $\geq 18$ years; (2) patients diagnosed between 2010 and 2012; (3) patients with a prostate tumor; (4) patients underwent radical surgery or brachytherapy; (5) patients without distant metastases or lymphatic metastases. The exclusion criteria were: (1) Patients with polygenic tumor; (2) patients with carcinoma in situ; (3) patients with incomplete tumor type, differentiation degree and staging; (4) patients with incomplete follow-up data; (5) patients died within 30 days. Patients were staged using the American Joint Committee on Cancer (AJCC)/Union for International Cancer Control (UICC) TNM staging system (seventh edition), and pathological staging was performed according to the criteria revised by Gleason in 1992.(11)

\section{grouping}

The patients were divided into the radical prostatectomy group and the brachytherapy group. For subgroup analysis, the patients were divided into 5 subgroups, including G2T1c, G3T1c, G2T2a, G3T2a and G3T3b according to pathological staging and T staging. Random matching was performed based on age and PSA level.

\section{outcomes}


The outcomes included overall survival (OS) and prostate cancer-specific death time (PCSDT). OS referred to the time from the first day after operation to death due to any cause. No death after October 2017 was included. PCSDT referred to the time from the first day after operation to death caused by prostate cancer.

\section{statistical analysis}

Statistical analysis was performed using SPSS 13.0 software package (SPSS Inc., Chicago, IL, USA). Survival rate was calculated using Kaplan-Meier graphs, comparison of survival rates was made by logrank test. Continuous variables that met normal distribution were expressed as mean \pm standard deviation (SD), and comparison between groups used independent t-test. Continuous variables that did not meet normal distribution were expressed as median (range), and comparison between groups used Mann-Whitney $U$ test. Categorical data were expressed as frequency and percentage, and comparison between groups used Chi-square test. $P<0.05$ was considered to be statistically significant.

\section{Results}

\section{baseline characteristics in the two treatment groups}

The selection of patients from the SEER database for inclusion in the study, their grouping and subgrouping were shown in the Figure 1. The comparison of baseline characteristics between the two groups was shown in Table 1. There were significant differences of race, PSA level, marital status and staging between the two groups $(P<0.001)$. After random matching, the baseline characteristics of subgroups at T1-T3 stages were with no significant difference $(P>0.05)$.

\section{baseline characteristics and comparison of prognosis at T1 stage}

At G2T1c stage, there were 6,523 patients aged 62 (40-85) years with the PSA level at the first visit of 5.4 (0.1-98.0) $\mathrm{ng} / \mathrm{L}$ in the radical prostatectomy group, while there were 5950 patients aged 62 (37-71) years with the PSA level at the first visit of $5.3(0.1-14.6) \mathrm{ng} / \mathrm{L}$ in the brachytherapy group. OS and PCSDT were not significantly different between the radical prostatectomy group and the brachytherapy group $(P>0.05$, Fig.2).

At G3T1c stage, there were 7777 patients aged $65.3 \pm 6.1$ years with PSA level at the first visit of 6.2 (0.6$98.0) \mathrm{ng} / \mathrm{L}$ in the radical prostatectomy group, while there were 8496 patients aged $65.2 \pm 6.2$ years with PSA level at the first visit of $64(0.1-89.2) \mathrm{ng} / \mathrm{L}$ in the brachytherapy group. OS and PCSDT in the radical prostatectomy group were significantly higher than those in the brachytherapy group $(P<0.05$, Fig. 3$)$. 


\section{baseline characteristics and comparison of prognosis at T2 stage}

At G2T2a stage, there were 663 patients aged $65.0 \pm 7.0$ years with PSA level at the first visit of 5.7 (0.1$98.0) \mathrm{ng} / \mathrm{L}$ in the radical prostatectomy group, while there were 749 patients aged $65.8 \pm 7.4$ years with PSA level at the first visit of $5.4(0.1-98.9) \mathrm{ng} / \mathrm{L}$ in the brachytherapy group. OS and PCSDT were not significantly different between the radical prostatectomy group and the brachytherapy group $(P>0.05)$ (Fig. 4).

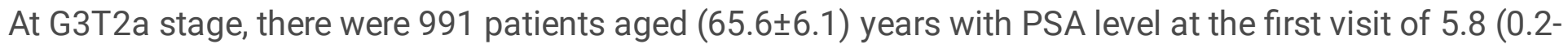
$58.6) \mathrm{ng} / \mathrm{L}$ in the radical prostatectomy group, while there were 1145 patients aged $(65.7 \pm 6.3)$ years with PSA level at the first visit of $6.2(0.1-78.5) \mathrm{ng} / \mathrm{L}$ in the brachytherapy group. OS in the radical prostatectomy group was longer compared to the brachytherapy group $(P=0.02)$, but PCSDT was not significantly different between the two groups $(P=0.339$, Fig.5).

\section{baseline characteristics and comparison of prognosis at T3 stage}

At G3T3b stage, there were 578 patients aged 70 (42-85) years with PSA level at the first visit of $249.5 \pm 314.3 \mathrm{ng} / \mathrm{L}$ in the radical prostatectomy group, while there were 287 patients aged 70 (49-85) years with PSA level at the first visit of $287.1 \pm 297.5 \mathrm{ng} / \mathrm{L}$ in the brachytherapy group. OS and PCSDT were not significantly different between the radical prostatectomy group and the brachytherapy group ( $P$ $>0.05$, Fig.6).

\section{Discussion}

The aim of this study was to compare the survival of patients with early-stage localized prostate cancer treated with either radical prostatectomy or brachytherapy. The results showed no significant difference in the OS and PCSDT between the two treatment methods in patients with G2T1c, G2T2a and G3T3b stage prostate cancer. But there was a significant difference in OS and PCSDT of patients with G3T1c stage and in OS of patients with G3T2a stage prostate cancer, with those treated with radical prostatectomy surviving longer. These results suggest that radical prostatectomy may be superior to brachytherapy in the treatment of low-risk localized prostate cancer.

Previous studies that compared the survival of patients with localized prostate cancer treated with these two methods have shown similar survival times. $(9,10)$ However, the aim of this study was to investigate the influence of cancer stages on the survival of patients. The TNM staging system of prostate cancer was designed by AJCC and UICC in 1992, aiming to determine the prognosis of patients and develop treatment regimen.(12) Patients in this study were divided into 5 subgroups according to pathological 
staging and T staging. Random matching was performed based on age and PSA level. In this study, a total of 33159 patients diagnosed with prostate cancer between 2010 and 2012 were analyzed, including 16532 cases of radical prostatectomy and 16627 of brachytherapy. The percentage of patients at T1 stage was higher, and OS as well as PCSDT at G3T1c stage in the radical prostatectomy group were both longer than those in the brachytherapy group, indicating that radical prostatectomy was still advantageous in the treatment of most patients with localized prostate cancer, whereas brachytherapy was also a good choice for patients at G2T1c stage. For patients at T2 and T3 stages, prognosis was not significantly different between the two treatments regardless of poorly- or well-differentiated prostate cancer. These patients may benefit from the use of external radiotherapy and chemotherapy. These results are partially supported by a previous study that also used the SEER database.[13] In that study patients $\geq 65$ years old with clinically localized prostate cancer were classified by their predicted life expectancy. The study found that patients with 10+ years life expectancy at diagnosis showed longer survival times after radical prostatectomy than radiotherapy (including brachytherapy) or observation, but this benefit was not seen in the patients with shorter life expectancy. However, although life expectancy and cancer stage are related, the study did not indicate any association between the two variables.(13)

For low-risk prostate cancer confined to the prostate gland, radical prostatectomy can achieve better prognosis by completely resecting the gland. The history of radical prostatectomy (as the preferred treatment of prostate cancer) can be traced back over one century.(14) A large randomized controlled study comparing radical prostatectomy and conservative treatment revealed that radical prostatectomy can significantly decrease distant metastasis and tumor-specific mortality for patients with localized prostate cancer. (15) Radical prostatectomy has been a "gold standard" in the treatment of prostate cancer for a long time. However, there has been controversy over the therapeutic effects of radical prostatectomy and brachytherapy in the treatment of prostate cancer. Some studies have demonstrated that brachytherapy can not only prolong distant metastasis-free survival of patients, but also prolong tumor-specific survival of patients.(16) Tumor tissues have different responses to radiotherapy compared to normal tissues, and $\alpha / \beta$ ratio is an indicator measuring the response. Tissues and tumors with low $\alpha / \beta$ ratio are sensitive to low-dose sustained radiation, while tissues and tumors with high $\alpha / \beta$ ratio are sensitive to high-dose radiation.(17) The radiobiological data suggest that $\alpha / \beta$ ratio is low in prostate cancer tissue, at 1.2-3.0Gy, indicating that sustained and low-dose radiation is lethal to prostate cancer.( 18) Brachytherapy can perform low-dose and sustained radiation to prostate tissue and part of the surrounding tissues. $\alpha / \beta$ ratio of the tissues surrounding the prostate is high. Moreover, dose distribution around the radiation source decreases inversely proportionally to the square of the distance from the radiation source, which means that dose at the center is the highest, and the dose decreases with the increase in the distance from the radiation source. Thereby, brachytherapy can achieve higher local control rate, protect most of the bladder and rectum, as well as reduce complications.(19) Some studies with large sample size investigating the complications of radical prostatectomy and brachytherapy in the treatment of localized prostate cancer have shown that complications involving sexual function and urinary control are significantly higher with radical prostatectomy compared to brachytherapy, while the main complication of brachytherapy is stimulation of the urethra. $(20,21)$ With 
the improvement of brachytherapy technology and revolution of radiological technology, numerous of studies have demonstrated that the 5-year tumor-free survival for patients with low-risk prostate cancer treated by brachytherapy alone is up to $85-97 \%$, which is $93-97 \%$ for moderate-risk patients and $79-88 \%$ for high-risk patients. (18) However, radical prostatectomy has better prognosis for patients with low-risk prostate cancer compared to brachytherapy, suggesting that brachytherapy still needs improvement to treat prostate cancer.

Although this study compared the prognosis between radical prostatectomy and brachytherapy comprehensively and in detail, it still had the following limitations. (1) The SEER database recorded no information of postoperative chemotherapy and other treatments, which may affect the accuracy of determining prognosis. (2) The differences in the incidence of various pathological stages and T stages led to extremely few patients at some stages and huge differences in the comparison. Therefore, only 5 subgroups were involved. (3) Data used in this study were from America between 2010 and 2012. The surgical methods and brachytherapy technology at that time were limited to a certain degree. Thus, the present study may not represent the state of the current technology.

\section{conclusion}

In summary, the effect of radical prostatectomy was undeniable in the treatment of prostate cancer. Radical prostatectomy should be the preferred therapy for the treatment of patients with localized prostate cancer who have no significant surgical contraindications based on the willingness of the patients. However, brachytherapy can be used as an effective treatment method for patients who are not suitable for surgery or those who strongly object to surgery.

\section{List Of Abbreviations}

Surveillance, Epidemiology, and End Results (SEER).prostate specific antigen (PSA).overall survival (OS). prostate cancer-specific death time (PCSDT).American Association for the Study of the Prostate Cancer Strategy (CaPSURE).American Society of Brachytherapy (ABS).American Joint Committee on Cancer (AJCC)/Union for International Cancer Control (UICC).

\section{Declarations}

\section{Consent for publication}

approval

\section{Availability of data and material}


The dataset used and analyzed in this study are available from the corresponding author on reasonable request.

\section{Competing interests}

No competing both financial and non-financial interests exist.

\section{Funding}

None.

\section{Authors' contributions}

$\mathrm{QX}$ and $\mathrm{HL}$ conceived and designed the study. $\mathrm{XY}, \mathrm{YX}, \mathrm{XXY}$, and $\mathrm{YL}$ performed the data statistical. $\mathrm{HL}$ and QX wrote the paper. All authors read and approved the manuscript.

\section{Acknowledgements}

None.

\section{Ethics and Consent to participate}

All SEER data base information were deidentified by United States institutional review board approval.

\section{Consent to publish statement}

Not Applicable

\section{Ethics and Consent to Participate}

All SEER data base information were deidentified by United States institutional review board approval.

\section{References}

1.Cooperberg MR and Chan JM: Epidemiology of prostate cancer. World journal of urology 35: 849, 2017. 
2.Lee DJ, Mallin K, Graves AJ, Chang SS, Penson DF, Resnick MJ and Barocas DA: Recent Changes in Prostate Cancer Screening Practices and Epidemiology. The Journal of urology 198: 1230-1240, 2017.

3.Cooperberg MR, Lubeck DP, Mehta SS and Carroll PR: Time trends in clinical risk stratification for prostate cancer: implications for outcomes (data from CaPSURE). The Journal of urology 170: S21-25; discussion S26-27, 2003.

4.Walsh PC, DeWeese TL and Eisenberger MA: Clinical practice. Localized prostate cancer. The New England journal of medicine 357: 2696-2705, 2007.

5.Budaus L, Huland $\mathrm{H}$ and Graefen $\mathrm{M}$ : Controversies in the management of localized prostate cancer: radical prostatectomy still the standard of care. Critical reviews in oncology/hematology 84 Suppl 1: e24$29,2012$.

6.Fossati N, Wiklund P, Rochat CH, Montorsi F, Dasgupta P, Sanchez-Salas R, Canda AE, Piechaud T, Artibani W and Mottrie A: Robotic and Open Radical Prostatectomy: The First Prospective Randomised Controlled Trial Fuels Debate Rather than Closing the Question. European urology 71: 307-308, 2017.

7.Norderhaug I, Dahl O, Hoisaeter PA, Heikkila R, Klepp O, Olsen DR, Kristiansen IS, Waehre H and Bjerklund Johansen TE: Brachytherapy for prostate cancer: a systematic review of clinical and cost effectiveness. European urology 44: 40-46, 2003.

8. Yamada Y, Rogers L, Demanes DJ, Morton G, Prestidge BR, Pouliot J, Cohen GN, Zaider M, Ghilezan M and Hsu IC: American Brachytherapy Society consensus guidelines for high-dose-rate prostate brachytherapy. Brachytherapy 11: 20-32, 2012.

9.Sharkey J, Cantor A, Solc Z, Huff W, Chovnick SD, Behar RJ, Perez R, Otheguy J and Rabinowitz R: 103Pd brachytherapy versus radical prostatectomy in patients with clinically localized prostate cancer: a 12-year experience from a single group practice. Brachytherapy 4: 34-44, 2005.

10.Liu L, Han R and Liu C: Comparison of the efficacy of brachytherapy and radical prostatectomy in the treatment of localized prostate cancer - a meta-analysis. Journal of Modern Urology 13: 288-290, 2008.

11.Weiss MA: Urologic Surgical Pathology/ Urologic surgical pathology. Mosby 188, 1997.

12.Bostwick DG, Myers RP and Oesterling JE: Staging of prostate cancer. Seminars in surgical oncology 10: 60-72, 1994.

13.Sun M, Sammon JD, Becker A, Roghmann F, Tian Z, Kim SP, Larouche A, Abdollah F, Hu JC, Karakiewicz PI, et al: Radical prostatectomy vs radiotherapy vs observation among older patients with clinically localized prostate cancer: a comparative effectiveness evaluation. BJU international 113: 200208, 2014. 
14.Schostak M, Miller K and Schrader M: Radical prostatectomy in the 21st century - the gold standard for localized and locally advanced prostate cancer. Frontiers of radiation therapy and oncology 41: 7-14, 2008.

15.Bill-Axelson A, Holmberg L, Filen F, Ruutu M, Garmo H, Busch C, Nordling S, Haggman M, Andersson SO, Bratell S, et al: Radical prostatectomy versus watchful waiting in localized prostate cancer: the Scandinavian prostate cancer group-4 randomized trial. Journal of the National Cancer Institute 100: 1144-1154, 2008.

16.Boehm K, Schiffmann J, Tian Z, Lesmana H, Larcher A, Mandel P, Karakiewicz PI, Graefen M, Schwarz $\mathrm{R}$, Krull A, et al: Five-year biochemical recurrence-free and overall survival following high-dose-rate brachytherapy with additional external beam or radical prostatectomy in patients with clinically localized prostate cancer. Urologic oncology 34: 119.e111-118, 2016.

17.Miralbell R, Roberts SA, Zubizarreta E and Hendry JH: Dose-fractionation sensitivity of prostate cancer deduced from radiotherapy outcomes of 5,969 patients in seven international institutional datasets: alpha/beta = $1.4(0.9-2.2) \mathrm{Gy}$. International journal of radiation oncology, biology, physics 82: e17-24, 2012.

18.Ritter M, Forman J, Kupelian P, Lawton C and Petereit D: Hypofractionation for prostate cancer. Cancer journal (Sudbury, Mass) 15: 1-6, 2009.

19.Tselis $\mathrm{N}$ and Zamboglou N: High-Dose-Rate Brachytherapy in the Treatment of Clinically Localized Prostate Cancer/ Radiotherapy in Prostate Cancer. Springer Berlin Heidelberg 211-224, 2014.

20.Ferrer M, Suarez JF, Guedea F, Fernandez P, Macias V, Marino A, Hervas A, Herruzo I, Ortiz MJ, Villavicencio $\mathrm{H}$, et al: Health-related quality of life 2 years after treatment with radical prostatectomy, prostate brachytherapy, or external beam radiotherapy in patients with clinically localized prostate cancer. International journal of radiation oncology, biology, physics 72: 421-432, 2008.

21.Frank SJ, Pisters LL, Davis J, Lee AK, Bassett R and Kuban DA: An assessment of quality of life following radical prostatectomy, high dose external beam radiation therapy and brachytherapy iodine implantation as monotherapies for localized prostate cancer. The Journal of urology 177: 2151-2156; discussion 2156, 2007.

\section{Tables}

Table 1 Baseline Characteristics 


\begin{tabular}{|c|c|c|}
\hline Characteristics & radical prostatectomy $(\mathrm{n}=16532)$ & brachytherapy(n=16627) \\
\hline 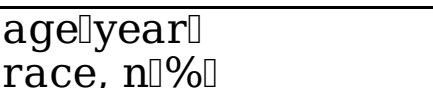 & $64 \llbracket 39-85 \square$ & $\begin{array}{ll}64 \square 37-85 \square & 0.772\end{array}$ \\
\hline white & $13522 \square 81.8 \% \square$ & $12503 \square 75.2 \% \square$ \\
\hline black & $2062 \square 12.5 \% \square$ & $2918 \square 17.6 \% \square$ \\
\hline other & $948 \square 5.7 \% \square$ & 1206ロ7.2\%ロ \\
\hline PSA $\square n g / l \square$ & $5.9 \square 0.10-99.9 \square$ & $5.9 \square 0.10-99.9 \square$ \\
\hline marital status, $\mathrm{n} \square \% \square$ & & \\
\hline married & 12574ロ76.1\%ם & 10922ロ65.7\%ם \\
\hline unmarried & 2980ロ18.0\%ロ & 3874凸23.3\%ロ \\
\hline unknown & $978 \square 5.9 \% \square$ & $1831011.0 \% \square$ \\
\hline stage, $\mathrm{n} \square \% \square$ & & \\
\hline G2T1c & 6523ロ39.5\%ロ & $5950 \square 35.8 \% \square$ \\
\hline G3T1c & 7777ロ47.0\%ם & 8496ロ51.1\%ロ \\
\hline G2T2a & 663ロ4.0\%ロ & 749๑4.5\%ロ \\
\hline G3T2a & 991 ८6.0\%ロ & $1145 \square 6.9 \% \square$ \\
\hline G3T3b & 578ロ3.5\%ロ & 287๑1.7\%ロ \\
\hline
\end{tabular}

\section{Figures}




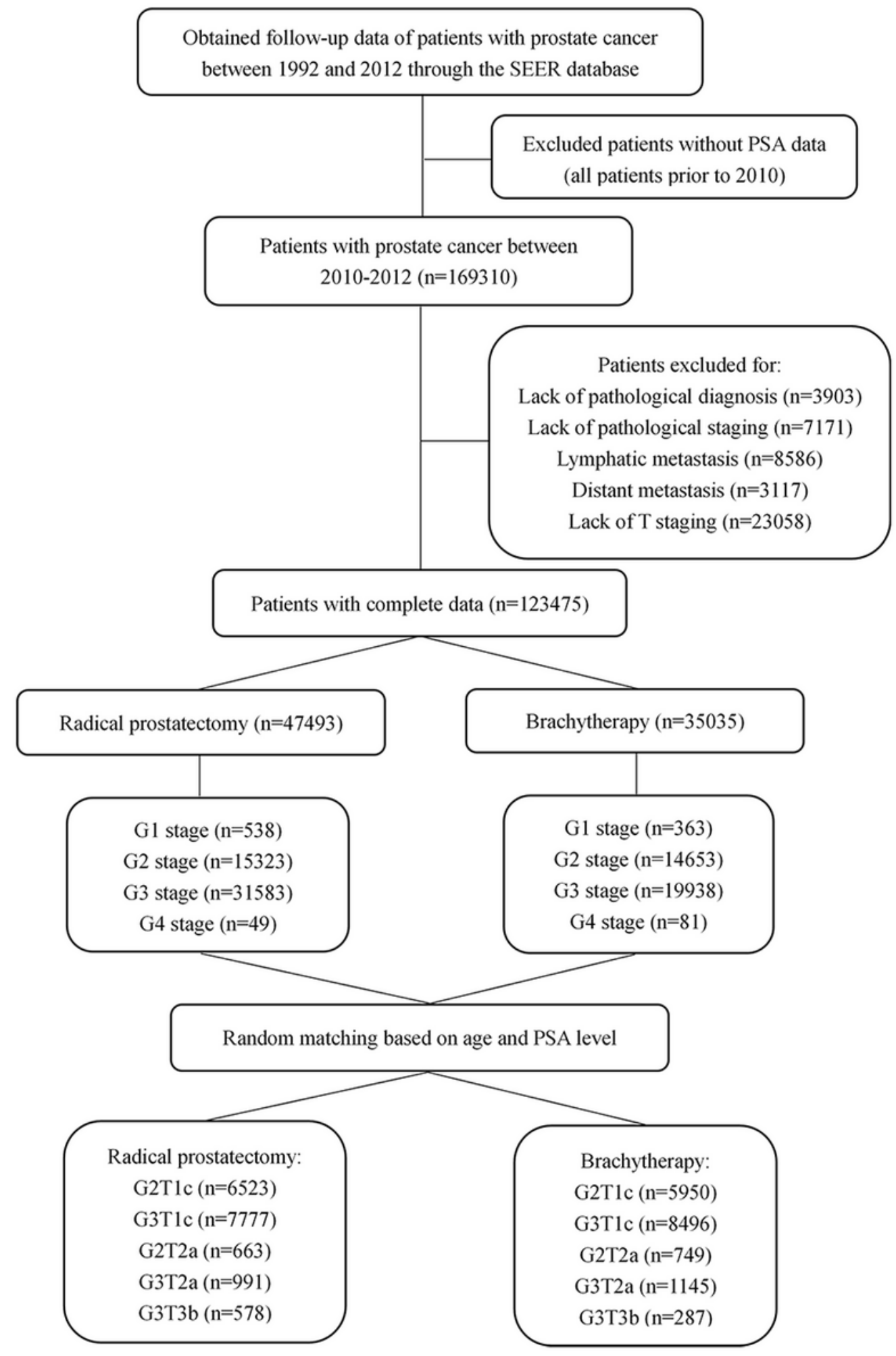

\section{Figure 1}

\section{Flowchart}



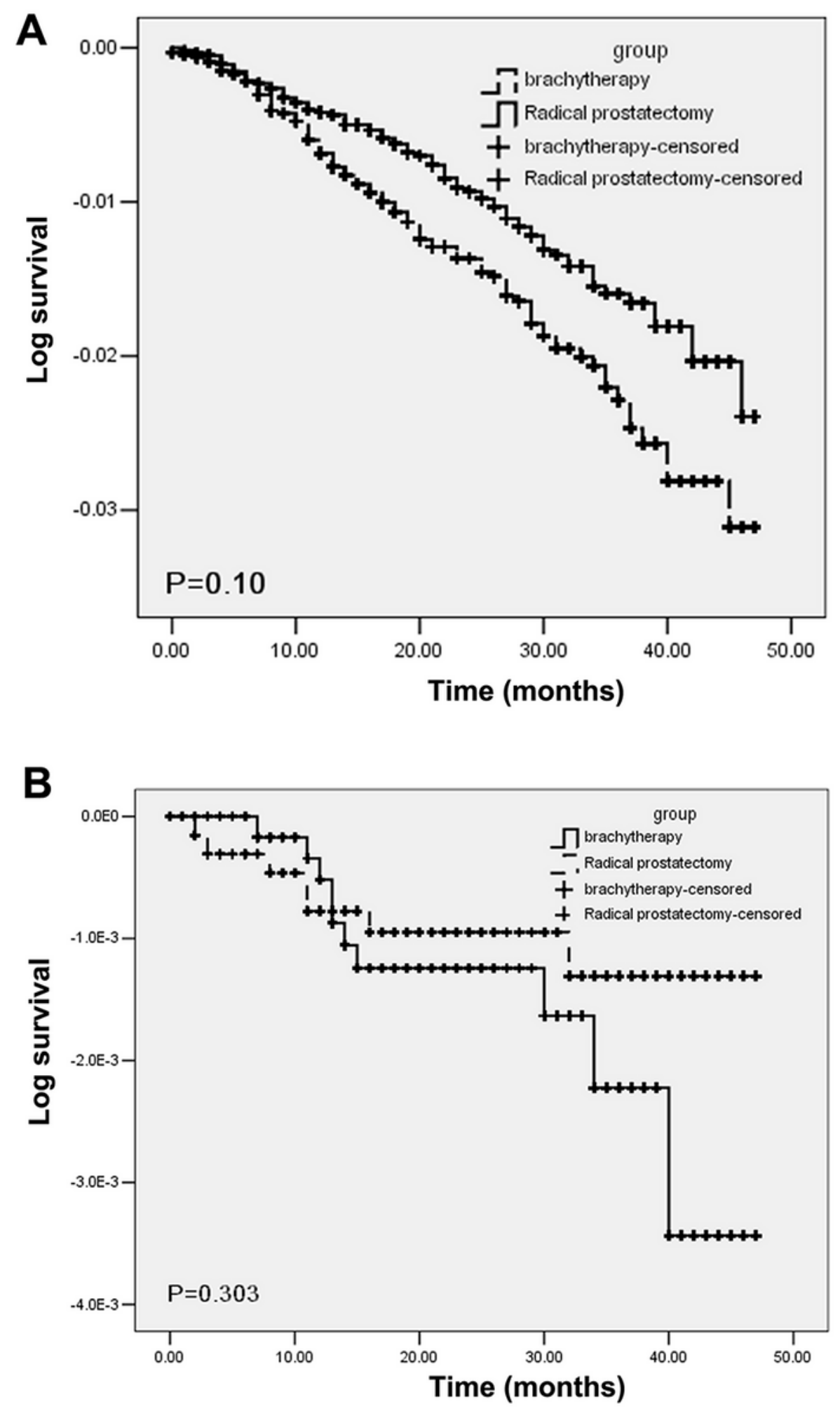

Figure 2

Kaplan-Meier graphs of survival in months of patients with stage G2T1c prostate cancer. OS (A) and PCSDT (B) in the radical prostatectomy group and brachytherapy group. 

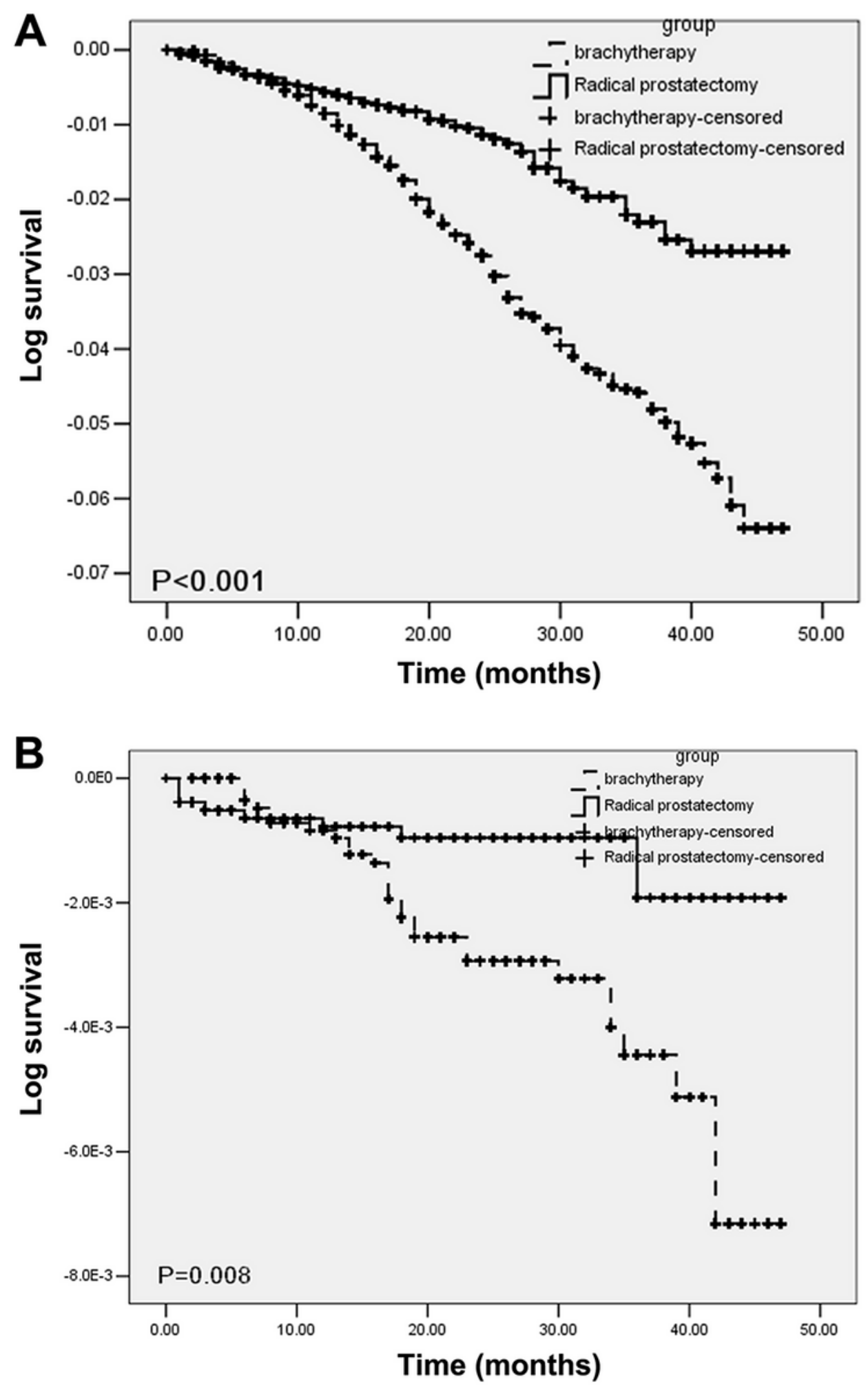

Figure 3

Kaplan-Meier graphs of survival in months of patients with stage G3T1c prostate cancer. OS (A) and PCSDT (B) in the radical prostatectomy group and brachytherapy group. 

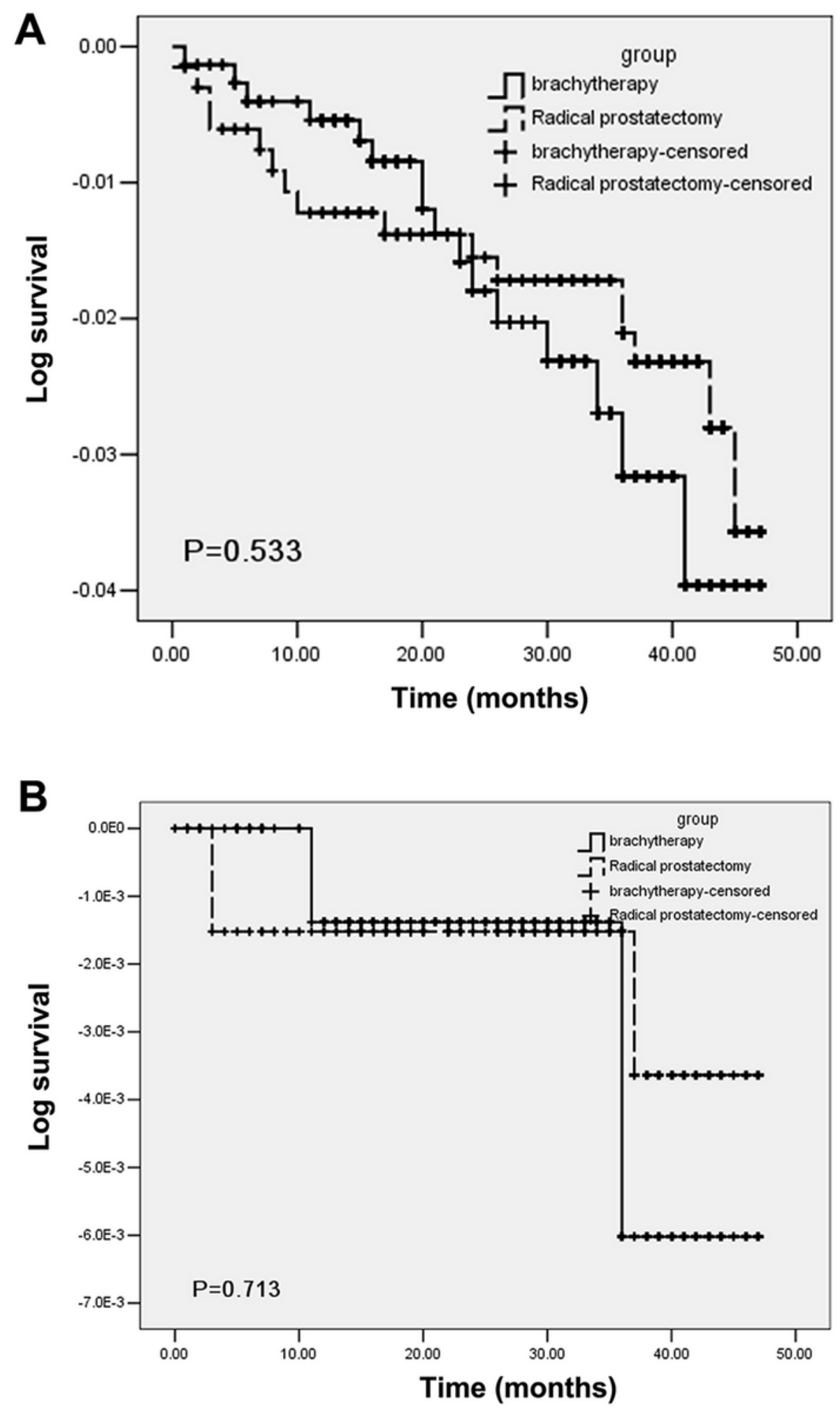

Figure 4

Kaplan-Meier graphs of survival in months of patients with stage G2T2a prostate cancer. OS (A) and PCSDT (B) in the radical prostatectomy group and the brachytherapy group. 

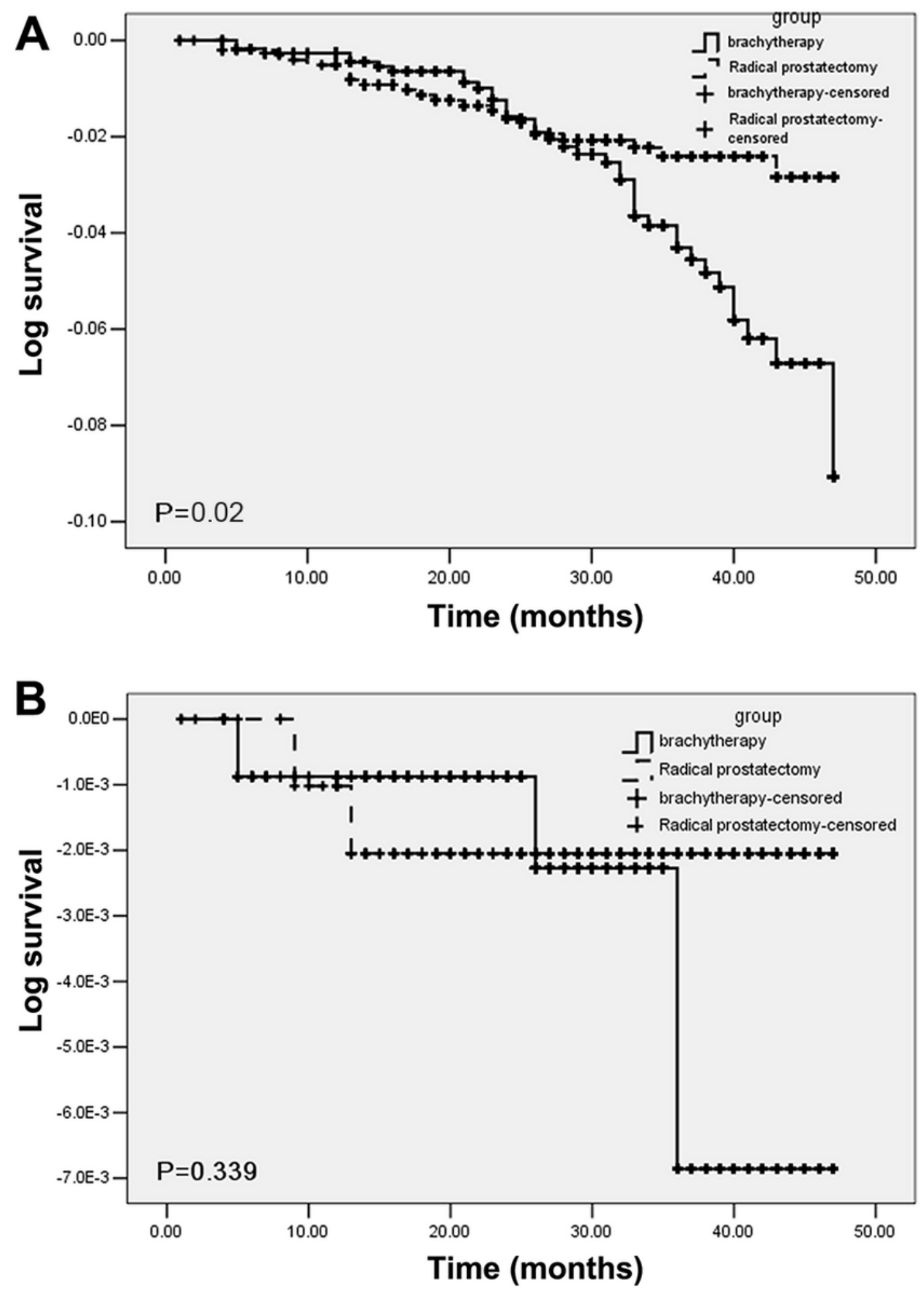

Figure 5

Kaplan-Meier graphs of survival in months of patients with stage G3T2a prostate cancer. OS (A) and PCSDT (B) in the radical prostatectomy group and the brachytherapy group. 

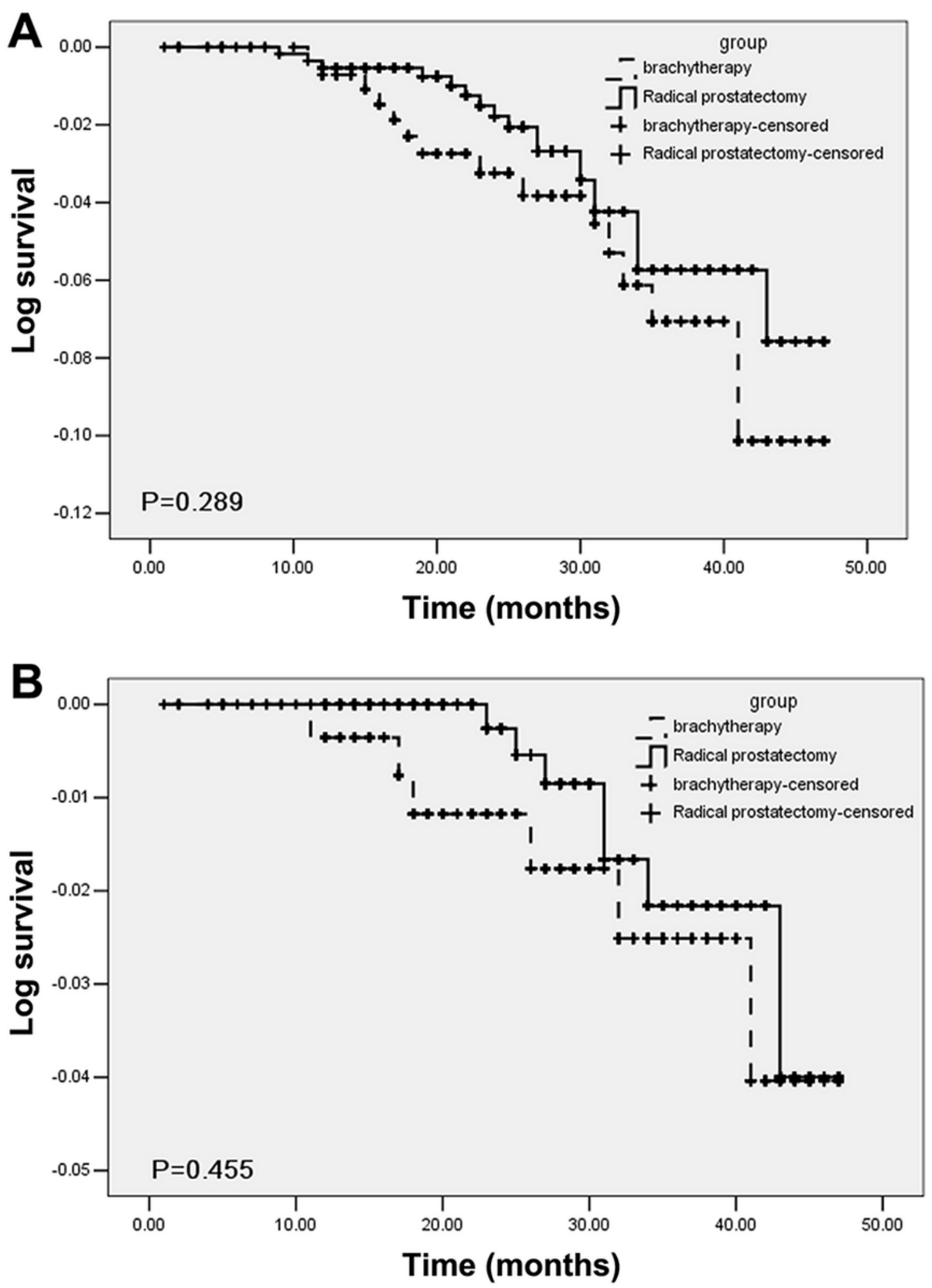

Figure 6

Kaplan-Meier graphs of survival in months of patients with stage G3T3a prostate cancer. OS (A) and PCSDT (B) at G3T3a stage in the radical prostatectomy group and the brachytherapy group 